\title{
Evaluation of transduction efficiency in macrophage colony-stimulating factor differentiated human macrophages using HIV-1 based lentiviral vectors
}

\author{
Francisco J Leyva', Joshua J Anzinger ${ }^{1}$, J Philip McCoy Jr², Howard S Kruth
}

\begin{abstract}
Background: Monocyte-derived macrophages contribute to atherosclerotic plaque formation. Therefore, manipulating macrophage function could have significant therapeutic value. The objective of this study was to determine transduction efficiency of two HIV-based lentiviral vector configurations as delivery systems for the transduction of primary human blood monocyte-derived macrophages.

Results: Human blood monocytes were transduced using two VSV-G pseudotyped HIV-1 based lentiviral vectors containing EGFP expression driven by either native HIV-LTR (VRX494) or EF1 $\alpha$ promoters (VRX1090). Lentiviral vectors were added to cultured macrophages at different times and multiplicities of infection (MOI). Transduction efficiency was assessed using fluorescence microscopy and flow cytometry. Macrophages transduced between 2 and 120 hours after culturing showed the highest transduction efficiency at 2-hours transduction time. Subsequently, cells were transduced 2 hours after culturing at various vector concentrations (MOls of 5, 10, 25 and 50) to determine the amount of lentiviral vector particles required to maximally transduce human monocytederived macrophages. On day 7, all transduced cultures showed EGFP-positive cells by microscopy. Flow cytometric analysis showed with all MOls a peak shift corresponding to the presence of EGFP-positive cells. For VRX494, transduction efficiency was maximal at an MOI of 25 to 50 and ranged between 58 and 67\%. For VRX1090, transduction efficiency was maximal at an $\mathrm{MOI}$ of 10 and ranged between 80 and $90 \%$. Thus, transductions performed with VRX1090 showed a higher number of EGFP-positive cells than VRX494.

Conclusions: This report shows that VSV-G pseudotyped HIV-based lentiviral vectors can efficiently transduce human blood monocyte-derived macrophages early during differentiation using low particle numbers that do not interfere with differentiation of monocytes into macrophages.
\end{abstract}

\section{Background}

Coronary artery disease is the leading cause of death in the United States and other Western societies [1]. Coronary artery disease develops as a consequence of lipid deposition and foam cell formation in the arterial wall leading to the development of atherosclerotic plaques [2]. Atherosclerosis is considered an inflammatory disease in which the major cell types implicated are macrophages, smooth muscle cells, and T lymphocytes [3]. Macrophages are present in virtually every atherosclerotic plaque and have an important role in foam cell and

\footnotetext{
*Correspondence: kruthh@nhlbi.nih.gov

'Experimental Atherosclerosis Section, National Heart, Lung, and Blood Institute, NIH, Bethesda, MD, USA

Full list of author information is available at the end of the article
}

atherosclerotic plaque formation through the uptake and accumulation of cholesterol [4].

Circulating blood monocytes differentiate into macrophages. Monocytes can migrate through the blood vessel wall into surrounding tissue, where they differentiate into macrophages and accumulate in pathological tissue sites in the body. Macrophages produce proinflammatory and proangiogenic mediators, and function as host cells for pathogens. Due to these functions, macrophages can contribute to the initiation and progression of a wide variety of diseases. Therefore, directly manipulating these hematopoietic cell subsets could have significant therapeutic value [5].

Human blood monocyte differentiation into macrophages can be induced in vitro using three different

\section{Ciomed Central}


methods: culture in 1) human serum (HS), 2) fetal bovine serum (FBS) with granulocyte-macrophage colony-stimulating factor (GM-CSF) or 3) FBS with macrophage colony-stimulating factor (M-CSF). In our experience, macrophages differentiated with HS or GMCSF with FBS show similar phenotype and morphology (i.e., round cells resembling fried eggs) [6,7]. However, the M-CSF differentiated monocyte-derived macrophage has a different phenotype characterized by an elongated shaped macrophage with numerous vacuoles corresponding to macropinosomes, and constitutive uptake of low-density lipoprotein (LDL) $[8,9]$.

Gene transfer methods have been attempted to manipulate gene expression in macrophages. Non-viral methods such as calcium phosphate precipitation, electroporation, and liposomal or polyethylenimine transfection are less time-consuming and allow use of a larger number of constructs per experiment than viral methods. However nonviral gene transfer methods are inefficient at transfecting macrophages [5]. Viral systems generally give higher gene transfer efficiency and longer expression time than nonviral systems, but only allow the transfer of small sizes (less than $8 \mathrm{~kb}$ ) of foreign DNA [10]. Viral methods using adenoviruses have reported high transduction efficiency, but their lack of integration into the host cell genome makes the expression of any transferred gene transient [11-14]. Retroviruses (except lentivirus) require cell division to integrate their DNA into the host genome to remain stably transduced [15]; therefore, the limited proliferative nature of primary human macrophages does not favor the use of this viral vector.

Lentiviruses like HIV have the capacity to infect nondividing and dividing cells and to integrate into the host cell genome [16-20]. Due to these characteristics, HIVbased lentiviral vectors have been proposed as good delivery system candidates for gene therapy, but the attempt to use them in clinical trials has raised concerns about their safety including the risk of genetic recombination leading to the generation of replication-competent retrovirus in humans. Further modifications in the packaging and genetic components of viral genes have been carried out to develop safer HIV-based lentiviral vector systems [21-24]. Due to our interest in gene manipulation of human M-CSF differentiated monocytederived macrophages, the objective of this study was to determine transduction efficiency of primary human blood M-CSF differentiated monocyte-derived macrophages transduced with two VSV-G pseudotyped HIV-1 based lentiviral delivery systems.

\section{Results}

\section{Determination of optimal time to transduce}

Macrophage cultures from the same donor (donor 1) were transduced with VRX1090 vector using an MOI of
50 (final concentration of $30 \times 10^{6}$ transducing units per $\mathrm{ml}, \mathrm{TU} / \mathrm{ml}$ ) at 2, 24, 48 and 120 hours after plating. On day 8, all cultures transduced with VRX1090 showed EGFP-positive cells by microscopic examination (Figure $1 \mathrm{~A})$. In addition, cell density assessed by phase microscopy was slightly decreased in cultures transduced at 24, 48 and 120 hours compared with 2 hours after plating. Flow cytometric analysis carried out on day 9 showed a peak shift in data histograms corresponding to the presence of EGFP-positive cells for all transduced cultures compared with non-transduced control cells (Figure 1A). These findings correlated with the qualitative results found by direct visualization of the cells with the fluorescence microscope. All transductions were highly efficient with values between 66 and $92 \%$ of cells showing EGFP fluorescence. There was a negative correlation $(\mathrm{r}=-0.99, \mathrm{p}=0.013)$ between time of transduction and \% EGFP-positive cells.

The results showed that the highest transduction efficiency was reached when monocytes were transduced 2 hours after plating. On the other hand, the amount of fluorescence intensity per cell did not correlate $(\mathrm{r}=$ $0.46, \mathrm{p}=0.54$ ) with time of transduction (Figure $1 \mathrm{~B}$ ). Considering these findings, in order to achieve the highest transduction efficiency, all following experiments were performed 2 hours after monocyte plating.

\section{Determination of optimal multiplicity of infection}

We next determined the MOI required during transduction to efficiently transduce human monocyte-derived macrophages. In the experiment shown in figures 2, 3 and $4 \mathrm{~A}$, macrophage cultures from donor 2 were transduced once at the optimal transduction time, determined above to be 2 hours after plating. Transduction was performed using two different lentivirus vectors VRX494 and VRX1090. Each transduction was carried out using different MOIs: $5,10,25$, and 50 at a final concentration of $3,6,15$, and $30 \times 10^{6} \mathrm{TU} / \mathrm{ml}$, respectively.

On day 7, all VRX494-transduced cultures showed EGFP-positive cells (Figure 2). On day 8, \% EGFP-positive cells and fluorescence intensity were quantified using flow cytometry. In all transduced cultures a peak shift corresponding to the presence of EGFP-positive cells was found (Figure 3). Transduction efficiency ranged between 8 and $58 \%$, and a positive correlation $(\mathrm{r}=$ 0.99, $\mathrm{p}=0.007$ ) between MOI and \% EGFP-positive cells was found. However, the fluorescence intensity per cell showed a trend toward lower values with higher MOIs used for transduction (Figure 4A).

Photomicrographs of cultures transduced with VRX1090 showed EGFP-positive cells in all conditions (Figure 2). However, at an MOI of 25 and 50 a decrease in cell density compared to non-transduced control was observed by phase microscopy. On day 8 , flow cytometry analysis was 

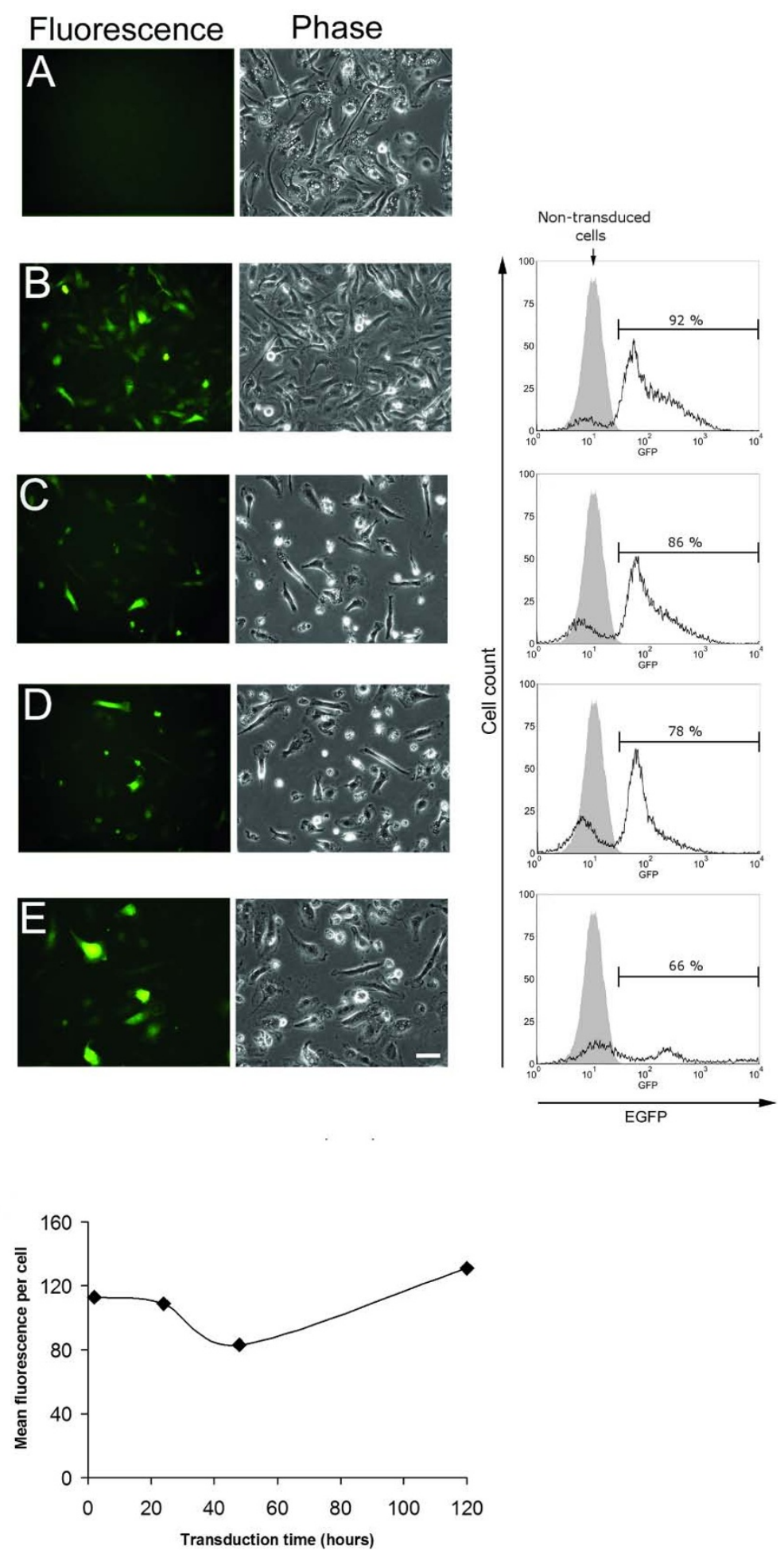

Figure 1 EGFP expression and flow cytometry analysis of human blood monocyte-derived macrophages transduced at different times Cells from donor 1 were transduced with lentivirus VRX1090 using an MOI of 50 (30 × 10 transducing units/ml) at 2 (B), 24 (C), 48 (D) and 120 (E) hours after cell plating. Control non-transduced cells are shown in A. Each row of the upper panel corresponds to the same microscopic field and respective flow cytometry histogram. Photomicrographs were taken on day 8 after cell plating. Scale bar $=50 \mu m$ and applies to all. Each bracketed region in the histogram corresponds to \% EGFP-positive cells and shaded area corresponds to non-transduced cell control. Flow cytometry was performed on day 9 after cell plating. Shown in lower panel is mean fluorescence intensity per EGFP-positive cell at different times after cell plating. 


\section{VRX494}
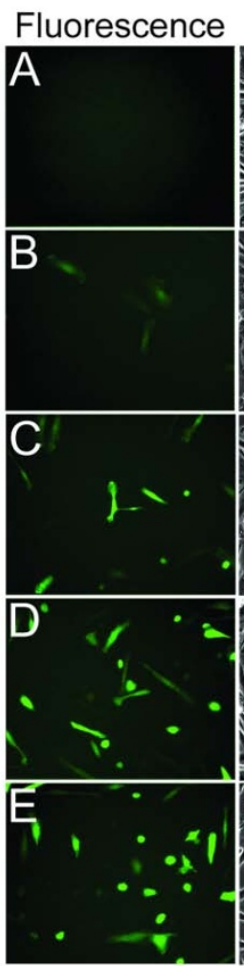

Phase

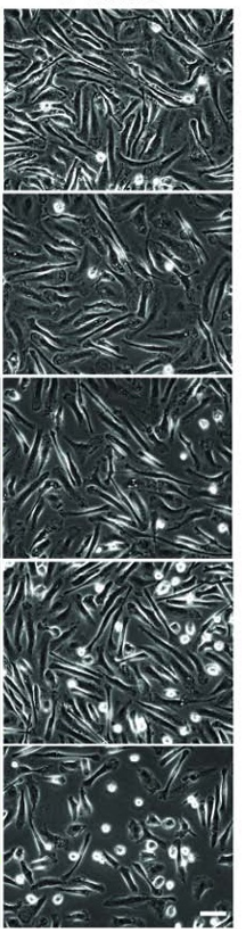

VRX1090

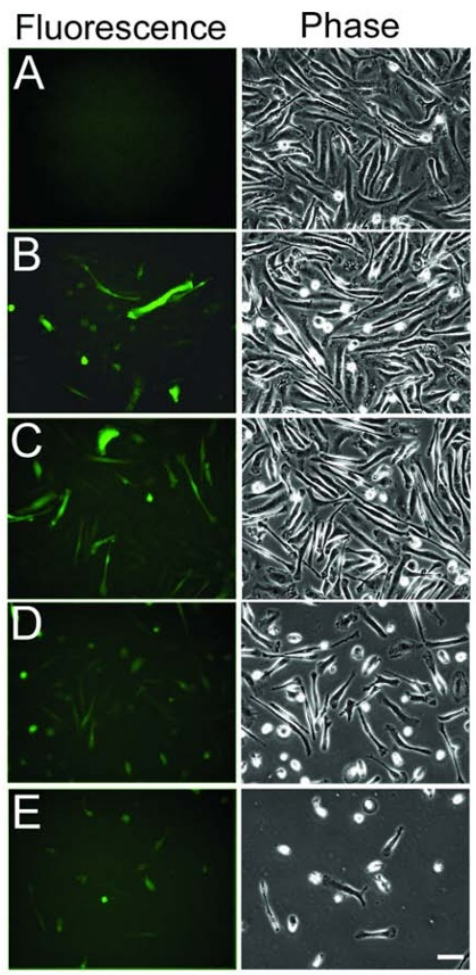

Figure 2 EGFP expression in human blood monocyte-derived macrophages transduced with VRX494 and VRX1090 at different MOIs Cells from donor 2 were transduced with lentivirus 2 hours after plating using MOls of 5 (B), 10 (C), 25 (D), and 50 (E) at a final concentration of $3,6,15$, and $30 \times 10^{6}$ transducing units $/ \mathrm{ml}$, respectively. Control non-transduced cells are shown in A. Each row corresponds to the same microscopy field. Photomicrographs were taken on day 7 after cell plating. Scale bar $=50 \mu \mathrm{m}$ and applies to all.

performed. Since the cell density of the culture transduced with an MOI of 50 was very low, there were insufficient cells for flow cytometry analysis. In all conditions, flow cytometry analysis histograms showed a peak shift for transduced cells when compared with non-transduced cells (Figure 3). All transductions were highly efficient with a range between 56 and 80\% EGFP-positive cells. However, \% EGFP and mean fluorescence intensity per cell showed no correlation with the MOIs used for transduction (Figures 3 and 4A).

To evaluate the role of the donor in the variability of these results, a second experiment using VRX1090 and VRX494 and different MOIs was repeated using blood monocytes from a different donor (donor 3). As shown in Table 1 and Figure 4B, the results obtained for each vector such as \% EGFP-positive cells and mean fluorescence intensity per cell trends were generally similar to the first experiment with donor 2. Also, vector copy numbers per cell were determined in this experiment and generally correlated with \% EGFP-positive cells
(Table 1). Cultures transduced at MOIs of 25 and 50 showed low cell density, and following flow cytometry there were not enough cells remaining for determination of vector copy numbers.

\section{Discussion}

Primary cells are usually more difficult to transfect or transduce than their similar immortalized cell lines [25], and macrophages are one of the most resistant cell types to gene transfer [10]. Therefore, obtaining efficient gene transfer in primary human blood monocyte-derived macrophages could be challenging.

In this report, we found that the best time to transduce human blood monocytes was 2 hours after cell plating. There were progressively fewer EGFP-positive cells when macrophage cultures were transduced at later times following plating of the cells. The differences between transduction time and time of flow cytometry quantification probably do not explain the negative correlation found between time of transduction and \% 


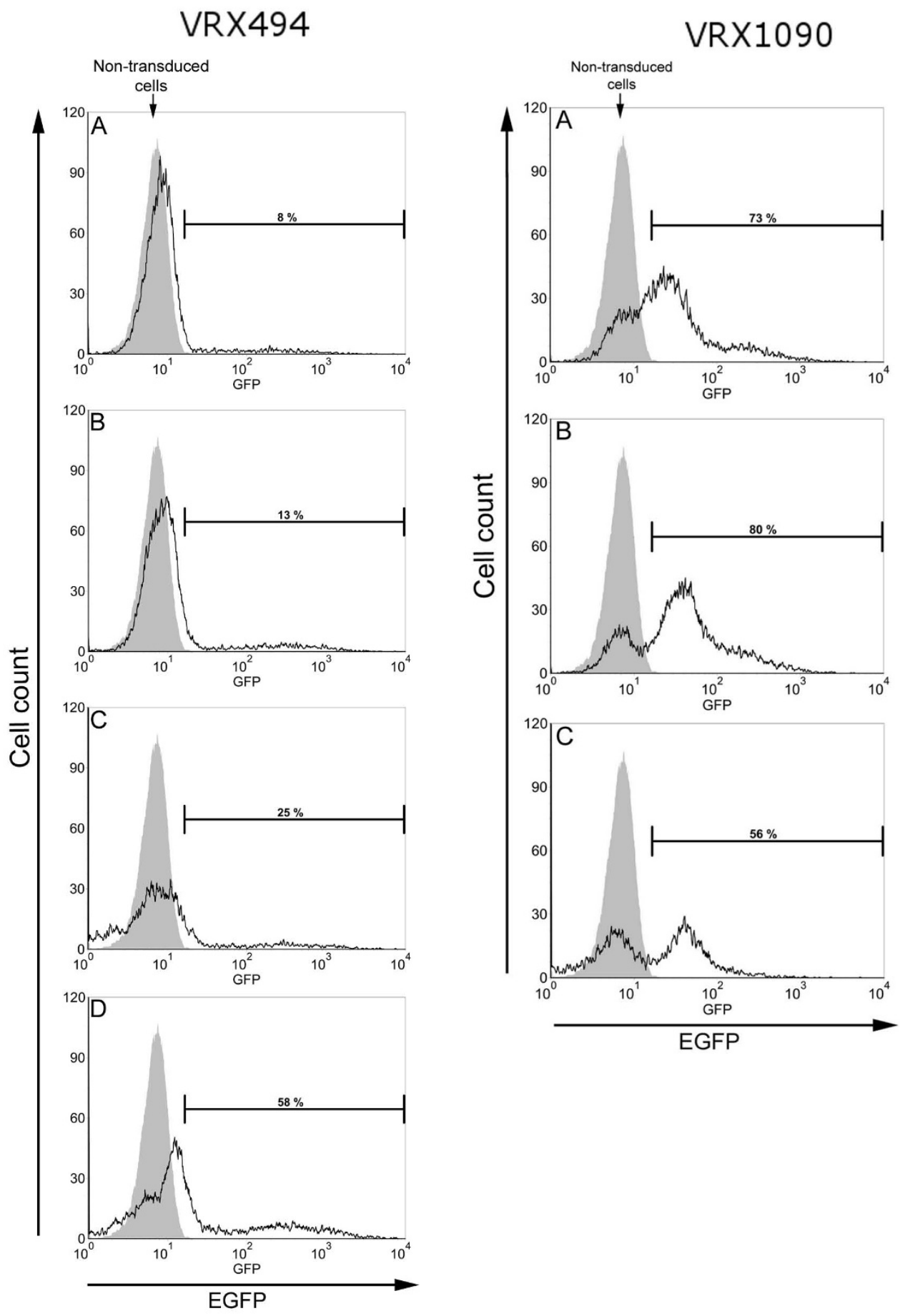

Figure 3 Flow cytometry analysis of human blood monocyte-derived macrophages transduced with lentivirus at different MOls. Cells from donor 2 were transduced with lentivirus VRX494 and VRX1090 two hours after plating using MOls of 5 (A), 10 (B), 25 (C), and 50 (D) at a final concentration of $3,6,15$, and $30 \times 10^{6}$ transducing units $/ \mathrm{ml}$, respectively. Each bracketed region in the histogram corresponds to \% EGFPpositive cells and shaded area corresponds to non-transduced cell control. Flow cytometry was performed on day 8 after cell plating. 


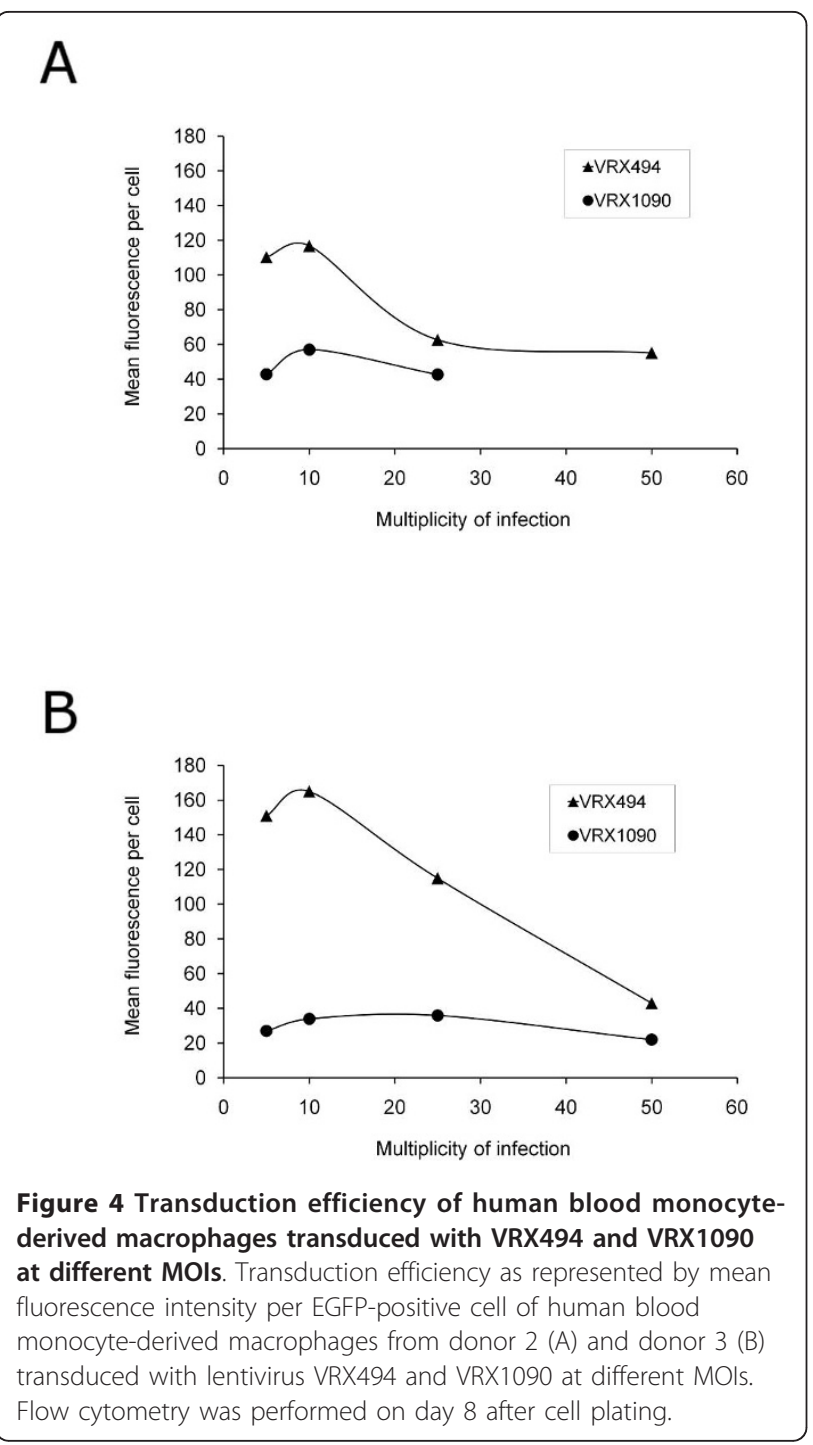

Table 1 Transduction efficiency of human blood monocyte-derived macrophages using different MOls

\begin{tabular}{lcc}
\hline MOI & \% EGFP-positive cells & G-tag copies per cell \\
\hline VRX494 & 23 & 9 \\
5 & 39 & 18 \\
10 & 67 & $\mathrm{nd}^{*}$ \\
25 & 56 & $\mathrm{nd}$ \\
50 & & \\
& & \\
VRX1090 & 83 & 37 \\
5 & 90 & 55 \\
10 & 74 & $\mathrm{nd}$ \\
25 & 44 & $\mathrm{nd}$ \\
50 & & \\
\hline
\end{tabular}

${ }^{*}$ nd $=$ not determined due to low cell number Human blood monocytederived macrophages for this experiment were obtained from donor 3 .
EGFP positive cells. EGFP is a stable protein with a turnover of approximately $10 \%$ in 3 hours, whose expression can be detected 24-48 hours after its cDNA has been transferred into various mammalian cell types [26]. Since all transductions in our cell cultures were performed between 72 hours and 192 hours before quantification, it is reasonable to conclude that by the time of flow cytometry quantification, all transduced cultures should have already reached their plateau of EGFP concentration. Thus, the difference observed between each group was likely due to differences in transduction efficiency rather than due to the differences in time of flow cytometry quantification. These findings suggest that monocyte-derived macrophages during the early phases of differentiation are highly transducible with VRX1090, but later they become less susceptible to transduction; the less differentiated the higher the transduction efficiency. However, we cannot exclude the possibility that more differentiated macrophages transduced for longer times would produce higher transduction efficiencies. In any case, transduction at later times after cell plating was associated with lower macrophage cell density, another factor favoring transduction at 2 hours after plating as the optimal time for transduction.

The possibility that macrophages phagocytosed EGFP derived from lentiviral solution contaminated with EGFP expressed during generation of the lentivirus from infected producer cells (i.e., pseudotransduction) cannot explain these findings. In such a case, the results would have been the opposite. In pseudotransduction, cells initially take up EGFP but then metabolize it without producing new EGFP. Thus, in pseudotransduction the cultures that were transduced later should have shown a higher proportion of EGFP-positive cells. Since this is the opposite of the pattern observed in this experiment, pseudotransduction was probably minimal.

Cultures transduced 24, 48 and 120 hour after plating showed a decrease in cell density when compared with the non-transduced control cultures transduced at 2-hours after plating. Since all cultures transduced 24 hours after plating were in the process of macrophage differentiation [27], it is possible that lentivirus addition in these cultures decreased cell proliferation or affected the differentiation of monocytes into macrophages to some degree thereby indirectly decreasing macrophage survival. The possibility of direct lentivirus-induced cell toxicity is remote, because it is well established that cell-induced toxicity correlates with exposure time. In our experiments, the culture with the longest exposure time to the lentivirus was the culture transduced 2 hours after plating. This culture showed the highest cell density compared with the other transduced cultures, so direct lentivirus-induced cell toxicity cannot explain the decrease in cell density. Mean fluorescence 
Table 2 Transduction efficiency* of human blood monocyte-derived macrophages using different viral systems

\begin{tabular}{lccccc}
\hline & $\begin{array}{c}\text { Transduction } \\
\text { efficiency }\end{array}$ & MOI & Viral system & $\begin{array}{c}\text { Differentiation } \\
\text { Method }\end{array}$ & Quantification technique \\
\hline Haddada H, et al. [13] & $40-80 \%$ & 100 & Adenovirus & HS & Beta-gal activity \\
Huang S, et al. [30] & $52 \%$ & 1000 & Adenovirus & M-CSF+FBS & Beta-gal activity \\
Schneider SD, et al. [33] & $20 \%$ & 100 & Adenovirus & HS & LacZ activity \\
De S, et al. [31] & $10 \%$ & 100 & Adenovirus & GM-CSF+FBS & Beta-gal activity \\
Foxwell B, et al. [12] & $>90 \%$ & 100 & Adenovirus & M-CSF+FBS & Beta-gal activity flow cytometry \\
Heider H, et al. [14] & $80 \%$ & 30 & Adenovirus & HS & GFP fluorescence microscopy \\
White S, et al. [34] & $15 \%$ & 1 & HIV/SIV based lentivirus & GM-CSF+HS & GFP fluorescence microscopy \\
Schroers R, et al. [20] & $30 \%$ & 100 & HIV based lentivirus & GM-CSF+FBS & YFP flow cytometry \\
Neil S, et al. [19] & 10 & HIV based lentivirus & HS & GFP flow cytometry \\
Ravot E, et al. [32] & $40 \%$ & 0.65 & HIV based lentivirus & HS+FBS & GFP flow cytometry \\
Lu Y, et al. [21] & $40 \%$ & 50 & HIV based lentivirus & HS+FBS & GFP fluorescence microscopy \\
Jarrosson-Wuilleme L, et al. [28] & $30 \%$ & 25 & HIV based lentivirus & GM-CSF+FBS & GFP flow cytometry \\
Zeng L, et al. [29] & $50 \%$ & 100 & HIV based lentivirus & HS+FBS & GFP fluorescence microscopy \\
Current report & $80-90 \%$ & 10 & HIV based lentivirus & M-CSF+FBS & EGFP flow cytometry \\
\hline
\end{tabular}

* Percentage transduced cells, values correspond to the highest value listed in the respective manuscript. $\mathrm{MOI}=$ multiplicity of infection, $\mathrm{HS}=$ human serum, GM-CSF = granulocyte-macrophage colony-stimulating factor, M-CSF = macrophage colony-stimulating factor, FBS = fetal bovine serum.

intensity per cell did not correlate with transduction time, suggesting that the amount of EGFP expressed per transduced cells is independent of transduction and macrophage differentiation time.

Our findings show that both lentiviruses at any of the various concentrations used were able to transduce monocyte-derived macrophages and produce EGFP in amounts sufficient for detection. Results of transducing monocyte-derived macrophages with VRX494 were similar to those observed in previous reports using viral transducing systems, higher MOIs resulted in higher frequency of cells that were transduced $[20,28,29]$. Transductions performed with VRX1090 showed a higher frequency of transduced cells than VRX494, but cells transduced with VRX494 showed higher fluorescence intensity per cell. These differences could be explained mostly by macrophage response during transduction (e.g., activation, promoter expression). Since each lentiviral vector used in this study requires a different promoter for protein expression, it is possible that differences in promoter and cell activity could have been responsible of the differences in the levels of EGFP expression. There is less possibility that intrinsic differences between the 2 lentiviruses (e.g., particle size, stability) could explain the differences found between both vectors since the same system was used to generate both lentiviruses.

Previous publications evaluating different viral systems for gene transfer in primary human monocyte-derived macrophages used the three methods previously mentioned to induce cell differentiation: HS, M-CSF and GM-CSF $[13,30,31]$. Table 2 shows the transduction efficiency (measured as frequency of positive cells), its quantification technique, viral system used, MOI, and blood monocyte-derived macrophage differentiation method reported by each publication [12-14,19-21, 28-34]. Only our study using HIV-derived lentivirus reached higher values comparable to those studies in Table 2 using adenovirus viral systems that required higher MOIs and as discussed above without viral DNA incorporation into the host cell genome which is required for stable transduction. However, when comparing our study with previous studies listed in Table 2 where HIVderived lentivirus was used to transduce human macrophages [19-21,28,29,32,34], only in our study was M-CSF used to induce macrophage differentiation. M-CSF-differentiated macrophages have been reported to show higher transduction efficiency than GM-CSF-differentiated macrophages when adenovirus viral systems are used [30]. This last finding is expected since adenovirus requires integrin $\alpha_{v} \beta_{5}$ for internalization [35], and M-CSF-differentiated macrophages express higher levels of integrin $\alpha_{\mathrm{v}} \beta_{5}$ than GM-CSF-differentiated macrophages [30]. VSV-G pseudotyped lentiviral vectors, such as the ones used in this report, have very broad tropism for cell infection [36]. However, it is possible that the transduction efficiency differences observed when comparing M-CSF with GM-CSF-differentiated macrophages may be due to differences in mechanisms available for uptake of VSV-G pseudotyped lentivirus by these two types of macrophages. In this regard, M-CSF differentiated human macrophages show very high levels of constitutive fluid-phase pinocytosis mediated by both macropinocytosis and micropinocytosis [8,9]. Fluid-phase pinocytosis (a non-receptor uptake mechanism) has been shown to mediate enhanced cellular transduction by 
vesicular stomatitis virus pseudotyped vectors as well as uptake of HIV by M-CSF differentiated human macrophages $[37,38]$.

Our finding that the optimal time to transduce M-CSF differentiated macrophages was better when these macrophages were less differentiated contrasts with the previous findings reported by Zeng et al. [29] in which less differentiated macrophages were more resistant to transduction. However, Zeng et al. reported transducing macrophages following differentiation with human serum, which produces the GM-CSF macrophage phenotype in contrast to the M-CSF macrophage phenotype we have studied here. Zeng et al. also transduced the macrophages in the presence of polybrene. We did not use polybrene in our experiments because we observed that polybrene was toxic to human M-CSF differentiated monocyte-derived macrophages (unpublished observation).

\section{Conclusions}

If higher MOIs are excluded, where donor-dependent a cell density decrease was usually observed, our study shows that transducing M-CSF differentiated monocytederived macrophages with VRX1090 lentivirus using an MOI of 10 consistently gives $80-90 \%$ transduction efficiency with no observed decrease in cell density. Thus, we show for first time that HIV-based lentiviruses can efficiently transduce M-CSF differentiated human blood monocyte-derived macrophages early during differentiation using a low MOI that will not interfere with the cell differentiation process or induce a decrease in cell density.

\section{Methods \\ Cell Culture}

Human blood monocytes were collected from three healthy blood donors (donor 1, 2 and 3) and purified with counterflow centrifugal elutriation of mononuclear cells [39]. Human blood cell collections were done by the Department of Transfusion Medicine, Clinical Center, National Institutes of Health, under a human subjects research protocol approved by a National Institutes of Health institutional review board and in agreement with the Helsinki Declaration. Cells were plated at $2 \times$ $10^{5}$ cells per $\mathrm{cm}^{2}$ in 6 -well CellBIND plates (Corning, Corning, NY), and cultured in RPMI 1640 medium (Mediatech, Herndon, VA) with 10\% FBS (Invitrogen, Carlsbad, CA). After 2-hours in a cell culture incubator with $5 \% \mathrm{CO}_{2} / 95 \%$ air at $37^{\circ} \mathrm{C}$, cells were rinsed 3 times with RPMI 1640 medium and then cultured in $3 \mathrm{ml}$ RPMI 1640 medium with $10 \%$ FBS, $50 \mathrm{ng} / \mathrm{ml} \mathrm{M-CSF}$, and $25 \mathrm{ng} / \mathrm{ml} \mathrm{IL-10,} \mathrm{both} \mathrm{of} \mathrm{the} \mathrm{latter} \mathrm{obtained} \mathrm{from}$ PeproTech (Rocky Hill, NJ). IL-10 was used to induce differentiation of monocytes into macrophages, since IL10 used together with M-CSF increases M-CSF receptor expression which enhances the macrophage differentiation process [27]. Cell cultures were fed with fresh medium after five days.

\section{Vector production}

Two vesicular stomatitis virus G protein (VSV-G) pseudotyped HIV-1 based lentiviral vectors encoding the enhanced green fluorescent protein (EGFP) driven by either the native HIV LTR promoter (VRX494, derived from NL4-3, Clade B) or the constitutive EF1 $\alpha$ promoter in a SIN configuration (VRX1090), both produced by VIRxSYS Corporation (Gaithersburg, MD) were used for these studies. Vectors were produced as previously described $[40,41]$. In brief, HEK293 cells were transfected using calcium phosphate with the VIRPAC packaging construct, a single packaging plasmid that coexpresses Gag-Pol, Tat, Rev, and VSV-G. Supernatant containing lentiviral particles were collected every $12 \mathrm{~h}$ from 24 to $48 \mathrm{~h}$ after transfection, concentrated by high-speed centrifugation at $10,000 \mathrm{~g}$ for $12 \mathrm{~h}$, and titered by Q-PCR (determination of number of transducing or infectious units per $\mathrm{ml}$ ) on HeLa-tat cells. Titers for VRX494 and VRX1090 were $3 \times 10^{9} \mathrm{TU} / \mathrm{ml}(\mathrm{p} 24=$ $47 \mathrm{ug} / \mathrm{ml})$ and $3.9 \times 10^{9} \mathrm{TU} / \mathrm{ml}(\mathrm{p} 24=92 \mathrm{ug} / \mathrm{ml})$ respectively.

\section{Transduction of macrophages}

Cultured monocyte-derived macrophages were transduced separately with lentiviral vectors VRX494 and VRX1090. Lentiviral vectors were added directly into each well containing $3 \mathrm{ml}$ of culture medium at different Hela-tat based multiplicities of infection (MOI-defined as the number of lentiviral particles able to transduce used per Hela-tat cell). Macrophage transduction efficiency, defined as percentage of transduced cells expressing EGFP and mean fluorescence intensity, was assessed qualitatively using an Olympus IX81 fluorescence microscope (Center Valley, PA) equipped with an FITC filter, and quantitatively using a FACSCalibur flow cytometer (Becton Dickinson Biosciences, San Jose, CA). Because a cell suspension was required for flow cytometry analysis, cells were scraped from each well after a 5minute incubation with Cellstripper solution (Mediatech), a non-enzymatic cell dissociation mixture of chelators. Non-transduced cells serving as controls also were analyzed with the cytometer. Gating was set on light scatter to include cells while excluding debris. EGFP fluorescence was measured using the $525 \mathrm{~nm}$ bandpass channel. EGFP positive cells were defined as those cells having fluorescence intensity greater than the non-transduced control cells. The mean geometric fluorescence intensity per EGFP-positive cell was determined. Data were analyzed using FCS Express version 3 (De Novo Software, Los Angeles, CA). 


\section{Determination of vector copy number per cell}

Transduced monocyte-derived macrophages were scraped from each well after a 5-minute incubation with Cellstripper solution (Mediatech). Total genomic DNA was extracted and purified using a QIAamp DNA Micro Kit from Qiagen (Valencia, CA). Vector-specific realtime PCR analysis using primers and probes specific for GFP cDNA (G-tag) were carried out to determine the number of integrated viral genomes. Cell numbers were estimated by measuring the number of $\beta$-globin DNA copies per sample by real-time PCR as previously described [42].

\section{Statistical Analysis}

Data was analyzed using Pearson's correlation coefficient. Statistical analyses were performed using Prism 4 for Windows version 4.00 (GraphPad Software, Inc., La Jolla, CA). Alpha error was set at $\mathrm{p}<0.05$.

\section{Acknowledgements}

The authors thank VIRXSYS Corporation for providing the HIV-based lentiviral vectors VRX494 and VRX1090 and determining vector copy numbers; Madaiah Puttaraju, Nikolay Korokhov, and Laurent M. Humeau from VIRXSYS for helpful suggestions about this work and manuscript; Peg Koelble from the NHLBI Office of Technology Transfer and Development; and Rex Robinson from the NIH library for the review of the manuscript. This research was supported in part by the NHLBI intramural research program.

\section{Author details}

'Experimental Atherosclerosis Section, National Heart, Lung, and Blood Institute, $\mathrm{NIH}$, Bethesda, MD, USA. ${ }^{2}$ Flow Cytometry Core, National Heart, Lung, and Blood Institute, $\mathrm{NIH}$, Bethesda, MD, USA.

\section{Authors' contributions \\ FJL carried out monocyte cell culture, macrophage differentiation, lentiviral transduction, fluorescence microscope analysis, cell harvesting for EGFP quantification, statistical analysis, and drafted the manuscript. JJA also carried out monocyte cell culture, macrophage differentiation, and fluorescence microscope analysis. JPM provided technical advice, carried out flow cytometry analysis and data interpretation. HSK conceived the study, participated in its design and coordination, and helped to draft the manuscript. All authors read and approved the manuscript.}

\section{Competing interests}

The authors declare that they have no competing interests.

Received: 28 September 2010 Accepted: 31 January 2011 Published: 31 January 2011

\section{References}

1. Heron M, Hoyert DL, Murphy SL, Xu J, Kochanek KD, Tejada-Vera B: Deaths: Final Data for 2006. In National Vital Statistics Report. Volume 57. Edited by: CDC. Hyattsville; 2009:1-80.

2. Kruth HS: Lipoprotein cholesterol and atherosclerosis. Curr Mol Med 2001, 1(6):633-653.

3. Libby P: Inflammation in atherosclerosis. Nature 2002, 420(6917):868-874.

4. Kruth HS: Macrophage foam cells and atherosclerosis. Front Biosci 2001, 6 : D429-455.

5. Burke B, Sumner S, Maitland N, Lewis CE: Macrophages in gene therapy: cellular delivery vehicles and in vivo targets. J Leukoc Biol 2002, 72(3):417-428

6. Kruth HS, Jones NL, Huang W, Zhao B, Ishii I, Chang J, Combs CA, Malide D, Zhang WY: Macropinocytosis is the endocytic pathway that mediates macrophage foam cell formation with native low density lipoprotein J Biol Chem 2005, 280(3):2352-2360.

7. Waldo SW, Li Y, Buono C, Zhao B, Billings EM, Chang J, Kruth HS: Heterogeneity of human macrophages in culture and in atherosclerotic plaques. Am J Pathol 2008, 172(4):1112-1126.

8. Zhao B, Li Y, Buono C, Waldo SW, Jones NL, Mori M, Kruth HS: Constitutive receptor-independent low density lipoprotein uptake and cholesterol accumulation by macrophages differentiated from human monocytes with macrophage-colony-stimulating factor (M-CSF). J Biol Chem 2006, 281(23):15757-15762.

9. Anzinger JJ, Chang J, Xu Q, Buono C, Li Y, Leyva FJ, Park BC, Greene LE, Kruth HS: Native low-density lipoprotein uptake by macrophage colonystimulating factor-differentiated human macrophages is mediated by macropinocytosis and micropinocytosis. Arterioscler Thromb Vasc Biol 2010, 30(10):2022-2031.

10. Burke B: Macrophages as novel cellular vehicles for gene therapy. Expert Opin Biol Ther 2003, 3(6):919-924.

11. Diao J, Smythe JA, Smyth C, Rowe PB, Alexander IE: Human PBMC-derived dendritic cells transduced with an adenovirus vectorinduce cytotoxic Tlymphocyte responses against a vector-encoded antigen in vitro. Gene Ther 1999, 6(5):845-853.

12. Foxwell B, Browne K, Bondeson J, Clarke C, de Martin R, Brennan F, Feldmann M: Efficient adenoviral infection with IkappaB alpha reveals that macrophage tumor necrosis factor alpha production in rheumatoid arthritis is NF-kappaB dependent. Proc Natl Acad Sci USA 1998, 95(14):8211-8215.

13. Haddada H, Lopez M, Martinache C, Ragot T, Abina MA, Perricaudet M: Efficient adenovirus-mediated gene transfer into human blood monocyte-derived macrophages. Biochem Biophys Res Commun 1993, 195(3):1174-1183.

14. Heider H, Verca SB, Rusconi S, Asmis R: Comparison of lipid-mediated and adenoviral gene transfer in human monocyte-derived macrophages and COS-7 cells. Biotechniques 2000, 28(2):260-265, 268-270.

15. Miller $D G$, Adam MA, Miller AD: Gene transfer by retrovirus vectors occurs only in cells that are actively replicating at the time of infection. Mol Cell Biol 1990, 10(8):4239-4242.

16. Corbeau P, Kraus G, Wong-Staal F: Transduction of human macrophages using a stable HIV-1/HIV-2-derived gene delivery system. Gene Ther 1998, 5(1):99-104

17. Miyake K, Suzuki N, Matsuoka H, Tohyama T, Shimada T: Stable integration of human immunodeficiency virus-based retroviral vectors into the chromosomes of nondividing cells. Hum Gene Ther 1998, 9(4):467-475.

18. Naldini L, Blomer U, Gallay P, Ory D, Mulligan R, Gage FH, Verma IM, Trono D: In vivo gene delivery and stable transduction of nondividing cells by a lentiviral vector. Science 1996, 272(5259):263-267.

19. Neil S, Martin F, Ikeda Y, Collins M: Postentry restriction to human immunodeficiency virus-based vector transduction in human monocytes. J Virol 2001, 75(12):5448-5456.

20. Schroers R, Sinha I, Segall H, Schmidt-Wolf IG, Rooney CM, Brenner MK, Sutton RE, Chen SY: Transduction of human PBMC-derived dendritic cells and macrophages by an HIV-1-based lentiviral vector system. Mol Ther 2000, 1(2):171-179.

21. Lu Y, Liu C, Zeng L, Lin Z, Dewhurst S, Gartner S, Planelles V: Efficient gene transfer into human monocyte-derived macrophages using defective lentiviral vectors. Cell Mol Biol (Noisy-le-grand) 2003, 49(7):1151-1156.

22. Wu X, Wakefield JK, Liu H, Xiao H, Kralovics R, Prchal JT, Kappes JC: Development of a novel trans-lentiviral vector that affords predictable safety. Mol Ther 2000, 2(1):47-55.

23. Levine BL, Humeau LM, Boyer J, MacGregor RR, Rebello T, Lu X, Binder GK, Slepushkin V, Lemiale F, Mascola JR, Bushman FD, Dropulic B, June CH: Gene transfer in humans using a conditionally replicating lentiviral vector. Proc Natl Acad Sci USA 2006, 103(46):17372-17377.

24. Wang GP, Levine BL, Binder GK, Berry CC, Malani N, McGarrity G, Tebas $P$, June $\mathrm{CH}$, Bushman FD: Analysis of lentiviral vector integration in HIV+ study subjects receiving autologous infusions of gene modified $C D 4+T$ cells. Mol Ther 2009, 17(5):844-850.

25. Hamm A, Krott N, Breibach I, Blindt R, Bosserhoff AK: Efficient transfection method for primary cells. Tissue Eng 2002, 8(2):235-245.

26. Li X, Zhao X, Fang Y, Jiang X, Duong T, Fan C, Huang CC, Kain SR: Generation of destabilized green fluorescent protein as a transcription reporter. J Biol Chem 1998, 273(52):34970-34975. 
27. Hashimoto S, Yamada M, Motoyoshi K, Akagawa KS: Enhancement of macrophage colony-stimulating factor-induced growth and differentiation of human monocytes by interleukin-10. Blood 1997, 89(1):315-321.

28. Jarrosson-Wuilleme L, Goujon C, Bernaud J, Rigal D, Darlix JL, Cimarelli A: Transduction of nondividing human macrophages with gammaretrovirus-derived vectors. J Virol 2006, 80(3):1152-1159.

29. Zeng L, Planelles V, Sui Z, Gartner S, Maggirwar SB, Dewhurst S, Ye L, Nerurkar VR, Yanagihara R, Lu Y: HIV-1-based defective lentiviral vectors efficiently transduce human monocytes-derived macrophages and suppress replication of wild-type HIV-1. J Gene Med 2006, 8(1):18-28.

30. Huang S, Endo RI, Nemerow GR: Upregulation of integrins alpha v beta 3 and alpha $v$ beta 5 on human monocytes and T lymphocytes facilitates adenovirus-mediated gene delivery. J Virol 1995, 69(4):2257-2263.

31. De SK, Venkateshan CN, Seth P, Gajdusek DC, Gibbs CJ: Adenovirusmediated human immunodeficiency virus-1 Nef expression in human monocytes/macrophages and effect of Nef on downmodulation of Fcgamma receptors and expression of monokines. Blood 1998, 91(6):2108-2117.

32. Ravot E, Comolli G, Lori F, Lisziewicz J: High efficiency lentiviral gene delivery in non-dividing cells by deoxynucleoside treatment. J Gene Med 2002, 4(2):161-169.

33. Schneider SD, Rusconi S, Seger RA, Hossle JP: Adenovirus-mediated gene transfer into monocyte-derived macrophages of patients with X-linked chronic granulomatous disease: ex vivo correction of deficient respiratory burst. Gene Ther 1997, 4(6):524-532.

34. White SM, Renda M, Nam NY, Klimatcheva E, Zhu Y, Fisk J, Halterman M, Rimel BJ, Federoff H, Pandya S, Rosenblatt JD, Planelles V: Lentivirus vectors using human and simian immunodeficiency virus elements. $J$ Virol 1999, 73(4):2832-2840.

35. Wickham TJ, Mathias P, Cheresh DA, Nemerow GR: Integrins alpha v beta 3 and alpha $v$ beta 5 promote adenovirus internalization but not virus attachment. Cell 1993, 73(2):309-319.

36. Yee JK, Friedmann T, Burns JC: Generation of high-titer pseudotyped retroviral vectors with very broad host range. Methods Cell Biol 1994, 43(Pt A):99-112.

37. Carter GC, Bernstone L, Baskaran D, James W: HIV-1 infects macrophages by exploiting an endocytic route dependent on dynamin, Rac1 and Pak1. Virology 2011, 409(2):234-250.

38. Quinn K, Brindley MA, Weller ML, Kaludov N, Kondratowicz A, Hunt CL, Sinn PL, McCray PB Jr, Stein CS, Davidson BL, Flick R, Mandell R, Staplin W, Maury W, Chiorini JA: Rho GTPases modulate entry of Ebola virus and vesicular stomatitis virus pseudotyped vectors. J Virol 2009, 83(19):10176-10186.

39. Kruth HS, Skarlatos SI, Lilly K, Chang J, Ifrim I: Sequestration of acetylated $\mathrm{LDL}$ and cholesterol crystals by human monocyte-derived macrophages. J Cell Biol 1995, 129(1):133-145.

40. Humeau LM, Binder GK, Lu X, Slepushkin V, Merling R, Echeagaray P, Pereira M, Slepushkina T, Barnett S, Dropulic LK, Carroll R, Levine BL, June $\mathrm{CH}$, Dropulic B: Efficient lentiviral vector-mediated control of HIV-1 replication in CD4 lymphocytes from diverse HIV+ infected patients grouped according to CD4 count and viral load. Mol Ther 2004, 9(6):902-913.

41. Lu X, Humeau L, Slepushkin V, Binder G, Yu Q, Slepushkina T, Chen Z, Merling R, Davis B, Chang YN, Dropulic B: Safe two-plasmid production for the first clinical lentivirus vector that achieves $>99 \%$ transduction in primary cells using a one-step protocol. J Gene Med 2004, 6(9):963-973.

42. O'Doherty U, Swiggard WJ, Malim MH: Human immunodeficiency virus type 1 spinoculation enhances infection through virus binding. J Virol 2000, 74(21):10074-10080.

doi:10.1186/1472-6750-11-13

Cite this article as: Leyva et al:: Evaluation of transduction efficiency in macrophage colony-stimulating factor differentiated human macrophages using HIV-1 based lentiviral vectors. BMC Biotechnology 2011 11:13.

\section{Submit your next manuscript to BioMed Central and take full advantage of:}

- Convenient online submission

- Thorough peer review

- No space constraints or color figure charges

- Immediate publication on acceptance

- Inclusion in PubMed, CAS, Scopus and Google Scholar

- Research which is freely available for redistribution 